\title{
The prevention of injuries in contact flag football
}

\author{
Yonatan Kaplan · Grethe Myklebust • \\ Meir Nyska - Ezequiel Palmanovich • \\ Jan Victor · Erik Witvrouw
}

Received: 23 August 2012/ Accepted: 27 November 2012

(C) Springer-Verlag Berlin Heidelberg 2012

\begin{abstract}
Purpose American flag football is a non-tackle, contact sport with many moderate to severe contact-type injuries reported. A previous prospective injury surveillance study by the authors revealed a high incidence of injuries to the fingers, face, knee, shoulder and ankle. The objectives of the study were to conduct a pilot-prospective injury prevention study in an attempt to significantly reduce the incidence and the severity of injuries as compared to a historical cohort, as well as to provide recommendations for a future prospective injury prevention study.

Methods A prospective injury prevention study was conducted involving 724 amateur male (mean age: $20.0 \pm 3.1$ years) and 114 female (mean age: $21.2 \pm$
\end{abstract}

This manuscript was submitted in partial fulfillment of Yonatan Kaplan's doctoral dissertation.

Y. Kaplan · E. Witvrouw

Department of Rehabilitation Sciences and Physiotherapy,

Ghent University, Ghent, Belgium

Y. Kaplan (ه)

Jerusalem Sports Medicine Center, Lerner Sports Center,

Hebrew University, Mount Scopus, 1 Churchill St.,

64460 Jerusalem, Israel

e-mail: sportmed@zahav.net.il

URL: www.jsportmed.com

G. Myklebust

Oslo Sports Trauma Research Center, Oslo, Norway

M. Nyska · E. Palmanovich

Department of Orthopedic Surgery, Meir Hospital,

Kfar Saba, Israel

J. Victor

Department of Physical Medicine and Orthopaedic Surgery,

Ghent University, Ghent, Belgium
7.2 years) players. Four prevention measures were implemented: the no-pocket rule, self-fitting mouth guards, ankle braces (for those players with recurrent ankle sprains) and an injury treatment information brochure. An injury surveillance questionnaire was administered to record all time-loss injuries sustained in game sessions.

Results There was a statistically significant reduction in the number of injured players, the number of finger/hand injuries, the incidence rate and the incidence proportion between the two cohorts $(p<0.05)$.

Conclusions This one-season pilot prevention study has provided preliminary evidence that finger/hand injuries can be significantly reduced in flag football. Prevention strategies for a longer, prospective, randomised-controlled injury prevention study should include the strict enforcement of the no-pocket rule, appropriate head gear, the use of comfortable-fitting ankle braces and mouth guards, and changing the blocking rules of the game.

Level of evidence II.

Keywords Contact flag football - Sports injuries . Prevention · Intervention study

\section{Introduction}

American flag football (AFF) is played in a similar manner to American football. However, there are several differences: AFF is played on a smaller field, the number of players per team ranges between five and nine players, and players are not allowed to wear pads of any kind. In AFF, instead of tackling the ball carrier, flags are clipped to a belt that is worn around the ball carrier's waist, and the removal of a flag is equivalent to a tackle. AFF provides participants with the opportunity to develop many of the 
same skills, tactics and strategies as American football, but without significant physical contact [30]. The AFF winter league in Israel (AFI) was established 25 years ago in Jerusalem and has rapidly expanded to a national league that consists of more than 90 teams (with over 1,000 players), including a men's, women's, high school and mixed league.

In a study on American army recruits, AFF was the third-leading producer of injuries in the sports and recreation category, behind basketball and softball [3]; thus, despite its lowered physical contact and injury susceptibility compared to tackle football, it has a relatively high injury incidence. These authors, as have others, proposed that further research or evaluation of prevention strategies is needed [11, 14, 29].

Three previously published epidemiological studies reported on injuries in flag football [3, 5, 17]. All three reported a high percentage of injuries to the fingers/wrist (ranging between 16 and $34 \%$ ), the knee (ranging between 11 and $16 \%$ ), the ankle (ranging between 8 and $12 \%$ ), the face and head $(18 \%)$ and the shoulder (9\%). Direct trauma was responsible for the vast majority of injuries (ranging between 64 and $75 \%$ ). In the latest of these three studies, conducted by the authors of the present manuscript, forty per cent of the hand/finger injuries were reported as a direct result of fingers being caught in the opposing player's pants [17]. Almost all players in this study wore pants with side pockets and refrained from playing with mouth guards, despite evidence that they have been shown to prevent oral and tongue injuries and that they might reduce the severity of concussions [4, 6, 21]. Both of the above are in violation of the International Flag Football Rules [12]. Although ankle braces have proven to be successful in reducing ankle injuries in sports, primarily in those players with recurrent sprains [9, 16, 23], very few players in the study cohort used them. There are no published studies that presented specific flag football mishap or injury prevention programs.

The aim of this study was twofold:

1. To conduct a one-season pilot-prospective injury prevention study (experimental cohort) in an attempt to significantly reduce the incidence and the severity of sports-related injuries in AFI, as compared to a historical cohort.

2. To provide recommendations for a future 2-season prospective injury prevention study.

\section{Materials and methods}

Pre-college American and Canadian males and females, who had registered to play in the AFI amateur league over the 2010/2011 season, participated in the study. Most study participants were of similar age, socio-economic background (had similar levels of education and were from the same ethnic communities) and played a similar number of games during the league season. All players were required to register via the AFI website. The players received information via electronic media that pertained to the study aims and protocol. A meeting was held prior to the season with all the paramedics and the AFI management, where the study's rationale and aims were explained, as well as the definitions of what constitutes a time-loss injury and an outline of the on-the-field questionnaire. A time-loss injury was defined as an injury that resulted in a player being unable to return to the current or future game [7].

Following agreement with the management of the AFI, four intervention measures were implemented:

1. The no-pocket rule. Players were not permitted to play with pants, which had open side pockets. The pockets were either glued (fabric glue) or taped by the principle author (YK) or by the players themselves.

2. Self-fitting mouth guards (Everlast ${ }^{\mathrm{TM}}$ Double Mouth Guard). Prior to the first game of the season, the principle author (YK) distributed mouth guards to each player with instructions related to the moulding and fitting process.

3. Ankle braces (Universal Ankle Stirrup DJO ${ }^{\mathrm{TM}}$ ). They were distributed to those players who reported a history of at least two previous sprains on the ipsilateral ankle, with accompanying instability and within the previous five-year period.

4. An injury treatment information brochure. The purpose of this brochure was to reduce the severity of the injuries [7]. It provided information on how to effectively treat an injury in the acute phase (P.R.I.C.E.M method [2, 13, 15]) as well as information pertaining to medical facilities in the event of an injury.

As the AFI is an amateur league, there are no official league practice sessions held during the season. All teams play one game per week. Injured players were either referred to their local physician or sent to the emergency unit of a local clinic or hospital.

The attending paramedics recorded only time-loss injuries throughout the playing season. These were collected manually by the principal author (YK) following the conclusion of all games that were scheduled for that day. A telephonic, in-depth injury surveillance questionnaire was administered within a day or two following the injury. The questionnaire was based on the internationally accepted consensus injury surveillance questionnaire recommendations of Fuller et al. [7] and was further adapted for AFF. Physicians were requested to provide a specific written 
diagnosis or to use a sport-specific injury coding system, such as the Orchard system [24]. This was done in order to reduce the possible risk of misclassification of injury.

In order to evaluate the compliance rate of the intervention methods used, all players who had received ankle braces were contacted telephonically upon the termination of the season. A brief questionnaire was completed including questions pertaining to the use of mouth guards as well as compliance with the no-pocket rule.

The ethics committee of the Meir Hospital, Kfar Saba, Israel, provided ethics approval for the study, and all players were required to sign a consent form prior to participation.

\section{Statistical analysis}

In order to compare the physical characteristics and severity of injury between the players in the historical cohort and the intervention cohort, the paired 2-tailed $t$ test for equality of means was used. For the purposes of crosstabulation of the study variables, the Pearson chi-square test was employed. The Pearson's chi-square test with Yates correction was used to determine whether there was a significant correlation between the two cohorts relating to body parts injured, the number of injuries reported and number of injured players. Statistical analysis was undertaken via the use of SPSS ${ }^{\circledR}$ predictive analytics software package (version 18.0), as well as the WinPepi package of statistical programs (PEPI-for-Windows) (version 11.18). With the assistance of the "Power and Precision" statistical power analysis software package, the calculation of a sample size for the planned study was computed. The $p$ value of statistical significance was $5 \%$ or less.

\section{Results}

There was no significant difference between the two cohorts with respect to their demographic data $(p<0.05)$ (Table 1).

There was a reduction in the number of injuries in all body parts, although it only reached statistical significance in the number of finger/thumb injuries $(p<0.05)$ (Fig. 1).

There was a significant reduction when comparing the total incidence rate/1,000 athletic exposures and the total incidence proportion between the two cohort seasons $(p<0.05)$ (Table 2). Although there was a positive trend towards a reduction in the severity of injuries and their distribution, this did not prove to be statistically significant (n.s).

Of the 838 potential participants, $638(76 \%)$ formed part of the pilot study cohort. Twenty-four per cent (200) of the players, who had initially registered through the AFI website, did not participate. Eight players $(1 \%)$ refused to sign the ethics form. The authors were not able to physically meet $56(6.7 \%)$ of the players in order to sign them up and give them the appropriate intervention. The rest (136 players or $16.2 \%$ ), although registered, never paid their registration fee and did not attend the season games. Fifty-two per cent (378/724) of the players reported having had at least one ankle sprain. Of these 378 players, 156 $(41.3 \%)$ received ankle braces.

Seventy $(45 \%)$ of the players who received ankle and mouth guards were successfully followed up post-season. Their compliance percentage values, as well as reasons provided for non-compliance, are summarised in Table 3.

\section{Discussion}

The most important finding of the present study was the reduction in finger/thumb injuries, which may be attributed to the enforcement of the no-pocket rule. As shown in Table 3, the majority of players contacted, reported $100 \%$ adherence with the no-pocket rule in the compliance questionnaire. Most players refused to purchase new shorts/pants without pockets, and therefore, their pockets were either glued or taped by the principle author (YK) or by themselves. Additionally, some players did not consent to taping/gluing of the pockets and some of the taped/glued pockets came undone throughout the season. The nopocket regulation should therefore be more stringently enforced, with referees imposing harsher penalties on teams who allow their players to play with pockets.

Although the mouth guards were self-fitting in nature, most of the players did not prepare them according to the instruction sheet provided. This may partly explain the discomfort reported, as they might not have been moulded

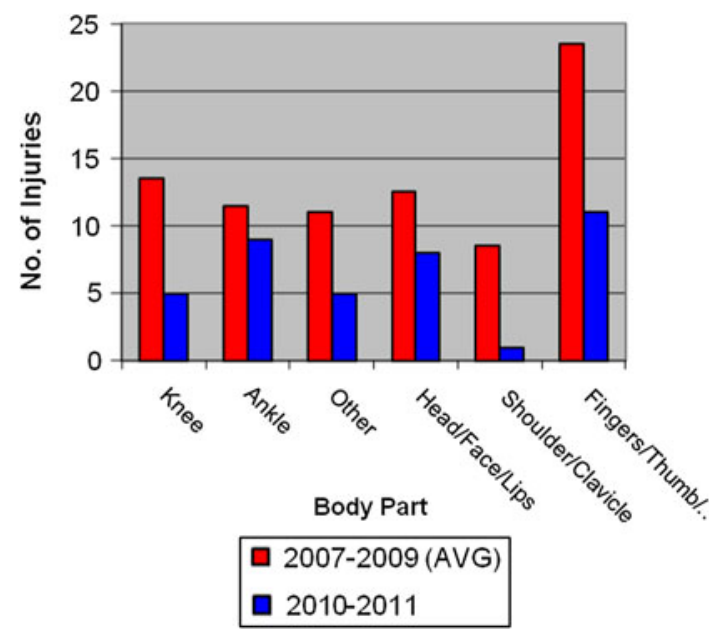

Fig. 1 Injured body parts comparison between the cohorts 
Table 1 Baseline demographic data

\begin{tabular}{|c|c|c|c|c|c|c|}
\hline Cohort & Avg no. games & Avg no. teams & Avg no. players & Avg age & Avg height (m) & Avg weight $(\mathrm{kg})$ \\
\hline Historical & 514 & 72 & 746 & 20.7 & 1.8 & 78.6 \\
\hline SD & & & & 5.3 & 0.1 & 17.1 \\
\hline Males & $423(82 \%)$ & $58(81 \%)$ & $626(84 \%)$ & 20.5 & 1.8 & 80.7 \\
\hline SD & & & & 4.9 & 1 & 16.9 \\
\hline Females & $91(18 \%)$ & $14(19 \%)$ & $120(16 \%)$ & 22.4 & 1.7 & 62.6 \\
\hline SD & & & & 7.6 & 0.9 & 9.2 \\
\hline Pilot & 464 & 64 & 724 & 20.2 & 1.8 & 74.3 \\
\hline SD & & & & 3.7 & 9.2 & 16.5 \\
\hline Males & 372 & 51 & 610 & 20.0 & 1.8 & 76.6 \\
\hline SD & & & & 3.1 & 8.6 & 15.8 \\
\hline Females & 92 & 13 & 114 & 21.2 & 1.7 & 60.9 \\
\hline SD & & & & 7.2 & 8.3 & 15.3 \\
\hline
\end{tabular}

properly (Table 3). In future studies, more attention should be placed on more comfortable, fitted mouth guards.

Thirty per cent of the players felt that both the ankle braces and mouth guards were unnecessary, this despite strong evidence that both significantly reduce the incidence and the severity of ankle and oral injuries, respectively $[4,6,9,16,23]$. To assist in reinforcing the maximal, beneficial preventative effect of the braces, better education is crucial. Many players reported that they felt that they only needed to wear the ankle brace if they had an injured ankle, when in actuality, the ankle brace was intended to prevent further injury in those players with a recurrent injury and not as a treatment measure. Regular telephonic and electronic communication may further assist in player compliance throughout the season.

The purpose of the injury treatment information brochure was not achieved as there was no significant difference in the injury severity. Although all the players were given the brochure on signing the ethics form, and it was placed on the field notice board, most players did not take the time to read the brochure and discarded it almost immediately. It is suggested that the brochure be sent to all the players via electronic mail, as well as to host a series of information seminars prior to the season, to better inform the players and team captains regarding its contents. This has been successfully executed in a previous injury prevention study [28].

It was decided not to use any form of knee bracing to prevent injury even though $83 \%$ of injuries to the knee in the historical cohort study were extrinsic in nature. Research is limited on the use of knee braces (prophylactic and functional) to potentially prevent knee ligament injury in the non-injured population [27]. Knee braces have not to date proven to be effective in reducing the number and severity of knee injuries [19, 26]. There is evidence, however, that neuromuscular preventative programs have been shown to reduce the incidence of noncontact knee injuries [1, 20, 25, 31], although they have

Table 2 Injury Result Data

\begin{tabular}{|c|c|c|c|c|c|c|}
\hline Cohort & $\begin{array}{l}\text { Avg no. injured } \\
\text { players }\end{array}$ & $\begin{array}{l}\text { Avg no. } \\
\text { injuries }\end{array}$ & $\begin{array}{l}\text { Avg no. players } \\
\text { injured in league }\end{array}$ & Athlete exposures & $\begin{array}{l}\text { Total incidence/ } \\
1,000 \text { exposures }\end{array}$ & Total incidence proportion \\
\hline Historical (total) & 79.5 & 82 & $9.4 \%$ & $1,533,776$ & $\begin{array}{l}0.1 \\
(95 \% \text { CI } 0.1,0.1)\end{array}$ & $\begin{array}{l}10.7 \% \\
(95 \% \text { CI 9.1, 12.2) }\end{array}$ \\
\hline Males & $71(89 \%)$ & $73(90 \%)$ & $11 \%$ & 264,798 & $\begin{array}{l}0.3 \\
(95 \% \text { CI } 0.1,0.2)\end{array}$ & $\begin{array}{l}9.8 \\
(95 \% \text { CI 9.1, 14.2) }\end{array}$ \\
\hline Females & $8.5(11 \%)$ & $8.5(10 \%)$ & $7 \%$ & 10,920 & $\begin{array}{l}0.8 \\
(95 \% \text { CI } 0.3,0.1)\end{array}$ & $\begin{array}{l}8 \% \\
(95 \% \text { CI } 2.5,11.7)\end{array}$ \\
\hline Pilot (total) & 41 & 42 & $5.7 \%$ & 335,936 & $\begin{array}{l}0.1 \\
(95 \% \text { CI } 0.1,0.2)\end{array}$ & $\begin{array}{l}5.7 \% \\
(95 \% \text { CI 4.0, 7.4) }\end{array}$ \\
\hline Males & 35 & 36 & $5.7 \%$ & 226,920 & $\begin{array}{l}0.2 \\
(95 \% \text { CI } 0.1,0.2)\end{array}$ & $\begin{array}{l}5.7 \% \\
(95 \% \text { CI 3.9, 7.6) }\end{array}$ \\
\hline Females & 6 & 6 & $5.3 \%$ & 10,488 & $\begin{array}{l}0.6 \\
(95 \% \text { CI } 0.1,1)\end{array}$ & $\begin{array}{l}5.3 \% \\
(95 \% \text { CI } 1.2,9.4)\end{array}$ \\
\hline
\end{tabular}


Table 3 Non-compliance reasons and compliance rates

\begin{tabular}{|c|c|c|c|c|c|c|}
\hline \multirow[t]{2}{*}{ Reasons for non-compliance } & \multicolumn{2}{|l|}{$\%$} & \multicolumn{4}{|c|}{ Compliance rate } \\
\hline & Aircast & Mouth guard & $\%$ & Aircast & Mouth guard & No-pocket rule \\
\hline Forgot it & 16 & 22 & 0 & 23.5 & 20 & 6.6 \\
\hline Uncomfortable & 45 & 47 & $1-35$ & 22.1 & 25 & 1.6 \\
\hline Other & 9 & 0 & $36-70$ & 14.7 & 12.5 & 3.3 \\
\hline Not in pain, so not wearing & 16 & 0 & $71-99$ & 8.8 & 7.5 & 12.8 \\
\hline Could not find it & 0 & 13 & 100 & 30.9 & 35 & 75.4 \\
\hline Did not feel "necessary" & 13 & 19 & & & & \\
\hline
\end{tabular}

yet to be investigated in reducing injury risk in contacttype sports.

Although $11 \%$ of the injuries in the historical cohort study were to the shoulder region, no shoulder injury prevention methods were implemented. Other than changing game rules to reduce the incidence of player-on-player contact, previous attempts to reduce the impact of shoulder injuries by the use of pads have proven unsuccessful. The pads appear to "bottom out" under higher-impact loads and therefore offer little protection when the athlete may need it most $[10,18]$.

In order to achieve a higher level of evidence-based study, it would have been preferable for the study cohort to have been randomised into those who received the prevention measures and those who did not. This was not possible for numerous reasons. As the AFI is an amateur league, with no team coaches to monitor the interventions used, there existed the risk of the unplanned crossover effect, whereby players assigned by the randomisation to the control group may begin to have second thoughts and may decide, of their own accord, to wear the intervention measures provided. This phenomenon would pose a serious challenge in the analysis of the data [8]. As a result of the current evidence that both ankle braces and mouth guards may significantly reduce the incidence and severity of ankle and oral injuries, respectively, the ethics committee of the Meir Hospital, Kfar Saba did not approve of the randomisation of the study cohort.

As captain/management and player compliance are regarded as important factors in any prevention trial, certain key prevention ideas were not accepted by the AFI management, even though they could potentially be important injury prevention methods. These included headgear and changing the blocking nature of the game. Headgear, for example, has been shown to reduce the force of non-ball-related impacts to the head [21, 22]. On analysis of the mechanism of injuries, and contact between players, blocking in particular was a significant cause of injuries (Fig. 2). Although chop blocks or blocks below the waist are not allowed, defensive players can get in the path of an offensive player in an attempt to grab the flag. Preventing or further limiting contact between players by changing the blocking rules of the game could reduce the incidence and severity of these injuries. As a member country of the International Federation of American Football (IFAF), the AFI management is bound by their rules and therefore did not agree to deviate from the rules on blocking set out in International Flag Football Rules [12].

Limitations of the study included the possibility of the underreporting of injuries by the players themselves. This may have been due to players being injured towards the end of the game, not wanting to report their injuries for personal reasons, as well as the refusal of some to comply with the questionnaire or their subsequent unreachability. The study included a specific-age population (pre-college male and female students), and therefore the possibility exists that the injury rate may be different in older or younger athletic populations. Although a telephonic, indepth questionnaire was administered by the principal author within a day or two following the injury, there were cases where the player's condition necessitated a follow-up medical investigation, and therefore, a final diagnosis was

(\%)
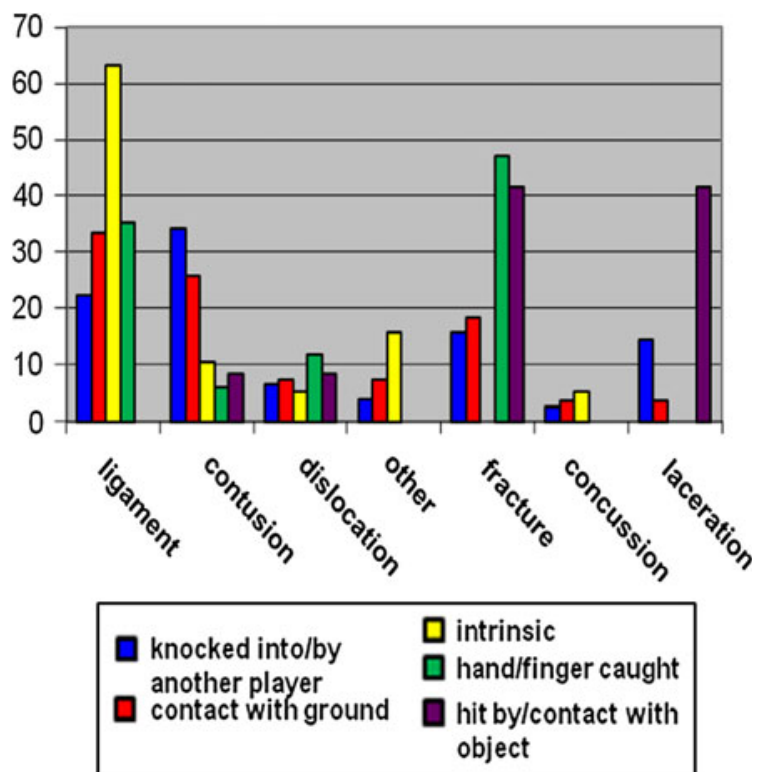

Fig. 2 Injury type versus injury mechanism 
only made 7-14 days post-injury. Although the authors felt that this time period was short enough that players would not suffer from recall bias, the possibility still existed. Finally, this was a pilot study, with its limitations of time and methodological shortcomings. A longer, prospective injury prevention study utilising the above-mentioned measures is recommended.

\section{Conclusions}

This is the first known prevention study in American Flag Football and has provided preliminary evidence that finger/ hand injuries can be significantly reduced in flag football. This study may serve as a paradigm for future programs. Further development of prevention strategies is needed. This should involve the strict enforcement of the no-pocket rule and wearing the appropriate head gear. The authors suggest that in future studies, the mouth guards should be individually prepared for the players during the distribution process. The IFAF should consider making the use of mouth guards mandatory during play, and not only a recommendation as it presently is in accordance with International Flag Football Rules [12]. In an effort to further increase player compliance in future studies, several types of ankle braces should be tested prior to their distribution. The authors additionally recommend a trial period prior to any intervention, in order to ensure maximum comfort and therefore ensuring better compliance.

Acknowledgments The authors would like to thank Mrs. Tali Bdolah, MSc, Senior statistician, Hebrew University, Jerusalem, for her assistance with the statistical analysis, as well as Miss Sari Goldstein, BSc, for her editing assistance in preparing this manuscript.

\section{References}

1. Alentorn-Geli E, Myer GD, Silvers HJ, Samiyier G, Romero D, Lazaro-Haro C, Cugat R (2009) Prevention of non-contact anterior cruciate ligament injuries in soccer players. Part 1: mechanisms of injury and underlying risk factors. Knee Surg Sports Traumatol Arthrosc 17:705-729

2. Bleakley CM, O'Connor S, Tully MA, Rocke LG, Macauley DC, McDonough SM (2007) The PRICE study (protection rest ice compression elevation): design of a randomized controlled trail comparing standard versus cryokinetic ice applications in the management of acute ankle sprain. Musculoskelet Disord 8:125

3. Burnham BR, Copley GB, Shim MJ, Kemp PA, Jones BH (2010) Mechanisms of flag-football injuries reported to the HQ Air Force Safety Center a 10-year descriptive study, 1993-2002. Am J Prev Med 38(1 Suppl):S141-S147

4. Chalmers DJ, Langley JD (1999) New Zealand Injury Research Unit: helping shape injury prevention policy and practice. Inj Prev 5:72-75
5. Collins RK (1987) Injury patterns in women's intramural flag football. Am J Sports Med 15:238-242

6. Finch C, Braham R, McIntosh A, McCrory P, Wolfe R (2005) Should football players wear custom fitted mouthguards? Results from a group randomized controlled trial. Inj Prev 11:242-246

7. Fuller CW, Ekstrand J, Junge A, Andersen TE, Bahr R, Dvorak J, Hagglund M, McCrory P, Meeuwisse WH (2006) Consensus statement on injury definitions and data collection procedures in studies of football (soccer) injuries. Scand J Med Sci Sports 16: $83-92$

8. Gordis L (2009) Epidemiology, 4th edn. Saunders Elsevier Publication, Philadelphia, pp 140-143

9. Handoll HH, Rowe BH, Quinn KM, de Bie R (2001) Interventions for preventing ankle ligament injuries. Cochrane Database Syst Rev 3:CD000018

10. Harris DA, Spears IR (2010) The effect of rugby shoulder padding on peak impact force attenuation. Br J Sports Med 3: 200-203

11. Hootman JM, Dick R, Agel J (2007) Epidemiology of collegiate injuries for 15 sports: summary and recommendations for injury prevention initiatives. J Athl Train 42:311-319

12. International Flag Football (2009) 5 on 5/non-contact, Article 1 b. Available via: www.ifaf.info/media/download/205

13. Ivins D (2006) Acute ankle sprain: an update. Am Fam Physician 74:1714-1720

14. Janda DH (1997) Sports injury surveillance has everything to do with sports medicine. Sports Med 42:169-171

15. Järvinen TA, Järvinen TL, Kääriäinen $M$, Aärimaa V, Vaittinen S, Kalimo H, Järvinen M (2007) Muscle injuries: optimising recovery. Best Pract Res Clin Rheumatol 21:317-331

16. Karlsson J (2002) Ankle braces prevent ligament injuries. Lakartidningen 99:3486-3489

17. Kaplan Y, Myklebust G, Nyska M, Palmanovich E, Victor J, Witvrouw E (2012) The prevention of injuries in contact flag football. Clin J Sport Med, doi:10.1097/JSM.0b013e3182694870

18. Kerr ZY, Collins CL, Pommering TL, Fields SK, Comstock RD (2011) Dislocation/separation injuries among US high school athletes in 9 selected sports: 2005-2009. Clin J Sport Med 21: $101-108$

19. Martinek V, Friederich NF (1999) To brace or not to brace? How effective are knee braces in rehabilitation? Orthopade 28: $565-570$

20. Myklebust G, Engebretsen L, Braekken IH, Skjolberg A, Olsen OE, Bahr R (2007) Prevention of noncontract anterior cruciate ligament injuries in elite and adolescent female team handball athletes. Instr Course Lect 56:407-418

21. Navarro RR (2011) Protective equipment and the prevention of concussion-what is the evidence? Curr Sports Med Rep 10: 27-31

22. Niedfeldt MW (2011) Head injuries, heading, and the use of headgear in soccer. Curr Sports Med Rep 10:324-329

23. Olsen OE, Myklebust G, Engebretsen L, Holme I, Bahr R (2005) Exercises to prevent lower limb injuries in youth sports: cluster randomised controlled trial. BMJ 330:449

24. Orchard J (1995) Orchard sports injury classification system (OSICS). Sport Health 11:39-41

25. Pasanen K, Parkkari J, Pasanen M, Hiilloskorpi H, Makinen T, Jarvinen M, Kannus P (2008) Neuromuscular training and the risk of leg injuries in female floorball players: cluster randomized controlled study. BMJ 337:a295

26. Pietrosimone BG, Grindstaff TL, Linens SW, Uczekai E, Hertel J (2008) A systematic review of prophylactic braces in the prevention of knee ligament injuries in collegiate football players. J Athl Train 43:409-415

27. Rishiraj N, Taunton JE, Lloyd-Smith R, Woollard R, Regan W, Clement DB (2009) The potential role of prophylactic/functional 
knee bracing in preventing knee ligament injury. Sports Med 39:937-960

28. Soligard T, Nilstad A, Steffen K, Myklebust G, Holme I, Dvorak J, Bahr R, Andersen TE (2010) Compliance with a comprehensive warm-up programme to prevent injuries in youth football. $\mathrm{Br}$ J Sports Med 44:787-793

29. Thacker SB (2007) Editorial: public health surveillance and the prevention of injuries in sports: what gets measured gets done. J Athl Train 42:171-172
30. Wikipedia, the free encyclopedia. Article, Flag Football, Available via: http://en.wikipedia.org/wiki/Flag/football

31. Zebis MK, Bencke J, Andersen LL, Dossing S, Alkjaer T, Magnusson SP, Kjaer M, Aagaard P (2008) The effects of neuromuscular training on knee joint motor control during side cutting in female elite soccer and handball players. Clin J Sport Med 18:329-337 